\title{
HISTÓRIA, ACONTECIMENTO E LÍNGUA: UM OLHAR PARA OS MOVIMENTOS SOCIAIS ${ }^{1}$
}

Luciana Vedovato ${ }^{2}$

RESUMO: o presente trabalho tem por objetivo discutir algumas questões fundamentais para a Análise de Discurso: a história, o acontecimento e a língua. Como objeto de análise tomamos um movimento social de luta pela terra o Movimento dos Trabalhadores Sem Terra - MST, olhando para o modo como a história organiza alguns dizeres - como a ocupação da terra, por exemplo, e como esses dizeres se desdobram em materialidades como a língua. Partindo dessa reflexão, tomamos o MST como um acontecimento que rompe com a ordem da história e passa a descrever, registras e simbolizar suas materialidades a partir de uma posição contraditória, a partir da classe dos trabalhadores. Assim, a compreensão de língua, em uma escola do MST, não é sempre coincidente com a concepção de língua cristalizada e sedimentada que vemos de forma determinantes em outros espaços escolares.

Palavras-chave: Língua, História, MST

\section{HISTORY, EVENT AND LANGUAGE: A LOOK AT SOCIAL MOVEMENTS}

ABSTRACT: the present work aims to discuss some fundamental questions for Discourse Analysis: history, event and language. As an object of analysis we took a social movement of struggle for land the Movement of Landless Workers - MST, looking at the way history organizes some sayings - such as land occupation, for example, and how these sayings unfold in materiality such as the tongue. Based on this reflection, we take the MST as an event that breaks with the order of history and starts to describe, register and symbolize its materiality from a contradictory position, from the working class. Thus, the understanding of language, in a MST school, is not always coincident with the concept of crystallized and sediment language that we see in a determinant way in other school spaces.

Keyword: Language, History, MST

\footnotetext{
${ }^{1} \mathrm{O}$ texto em questão é uma adaptação da tese de doutoramento intitulada: Prática de Resistência: Educação $e$ ensino de língua em escola de assentamento, apresenta ao programa de pós-graduação em Letras da Universidade Federal do Rio Grande do Sul, em julho de 2017.

${ }^{2}$ Professora do curso de Letras da Universidade Estadual do Oeste do Paraná/Foz do Iguaçu e do Programa de Pós-Graduação Sociedade, Culturas e Fronteiras da mesma instituição. Email: lucianavedovato@yahoo.com.br
} 


\section{INTRODUÇÃO}

Ao pensarmos nos movimentos sociais como um todo e no Movimento dos Trabalhadores Sem Terra (doravante MST), de forma específica, precisamos refletir sobre o funcionamento do conjunto de regramentos sobre a normatividade social. No bojo de tal reflexão surgem temas como a distribuição de terra - como um eixo norteador central - mas surgem também outras materialidades que são construídas a partir do modo como a luta pela terra organiza o funcionamento de um conjunto de ações que passam a compor uma série de atravessamentos em grandes categorias como a História, a Linguagem, o Direto, currículo, etc. Pois a tais categorias poderíamos perguntar: De quem é a terra hoje disputada? Como ela foi distribuída? Como funcionam as leis que sobre ela falam? Quem as organizou? Quem determinou o conjunto de saberes a serem ensinados, entre eles a Língua Portuguesa, a gramática normativa, etc.?

Muitas dessas perguntas já foram problematizadas pelo questionamento ao modo como, no Brasil, por exemplo, vozes dissonantes da escrita oficial da história, questionam não apenas o modo como os portugueses aqui chegaram, mas também como impusera um conjunto de saberes, práticas - entre elas a própria língua - que ajudaram ao longo da linearidade temporal a construir argumentos que abarcam desde um processo colonizador pacífico, até o imaginário de língua que temos hoje. Tais problematizações marcam um campo a ser trabalhado para pensarmos como podemos pensar em outras escritas históricas, outras línguas, outras literaturas, etc.

Assim, considerando os apontamentos acima, o objetivo do presente artigo é apresentar alguns dos principais conceitos da Análise do discurso e como tais conceitos pensados dentro dos estudos materialistas podem contribuir para debatermos questões que estão vinculadas às lutas e resistências que são construídas contra as formas de simbolização e organização das materialidades que contribuem para a construção das desigualdades estruturais e sociais. Para tanto, trataremos aqui do Discurso, da História e do Acontecimento. Essas três categorias nos importam, pois no decorrer de nosso trabalho apresentaremos a constituição do MST como um acontecimento Histórico que propiciou um conjunto de discursivizações em torno da luta e resistência primeiro, por meio das questões vinculadas a terra e, depois, pela transformação da sociedade. Ainda dentro deste capítulo, discutiremos o conceito de Formação Ideológica que, em nosso trabalho, trataremos a partir da perspectiva da infraestrutura. 


\section{A HISTÓRIA: UMA REORGANIZAÇÃO DOS MODOS DE NARRAR}

Na França, da década de 60 , os movimentos de esquerda atraem novas formas de compreensão da linguagem que se desenvolvem no seio de mudanças políticas, especialmente na Europa, que vai culminar com os movimentos de maio de $1968^{3}$. Surge a crise do Estruturalismo que, de acordo com Dosse, em História do Estruturalismo: o canto do cisne de 1967 aos nossos dias (1994), começava a provocar nos intelectuais um questionamento acerca dos métodos como estava sendo conduzida a ciência. Muitos deles, como Althusser, passaram a ter uma importância fundamental por refletir, dentro de uma concepção marxista, a sociedade regida pela ideologia. Os estudantes franceses começavam a questionar de forma mais contundente as práticas de disciplinarização e o pouco envolvimento dos intelectuais com as causas sociais. Ainda de acordo com Dosse (1994), a produção intelectual dos anos de 1965 a 1970 será fundamental para entrada da Linguística - via análise literária, inicialmente - no campo das Ciências que tinham as relações sociais como base da constituição dos objetos de análise, ou seja, a relação da língua com a História.

Nesse contexto é que Althusser (1999) propõe a teoria dos Aparelhos de Estado que concretiza um avanço nos escritos marxistas, pois fornece uma materialidade para ideologia. Aqui também é que Foucault (2005) consegue perceber que as instituições seriam o grande corpus para observar, na perspectiva dele, as relações de poder. A convergência das duas reflexões encontra-se no âmbito de destituir o fator econômico como determinante, para situar o motor da prática política nas relações sociais, nas tensões entre as instituições que,

\footnotetext{
${ }^{3}$ Alan Woods (2013) escreve um intrigante artigo para o www.marxismo.org.br narrando o Maio de 68 como a culminância de acontecimentos que seguiam desde 1931. Ele faz uma análise de que o movimento, liderado pelos estudantes da Nanterre e depois Soborne, foi uma resposta ao governo de Gaulles que acabara por implementar, no pós-guerra, o modelo capitalista francês, com isso todo o movimento dos operários de 1930 a 1940 ficou perdido. Woods até aponta para a análise de Trotsky que se o PCF fosse realmente socialista, poderia ter tomado o poder sem quase nenhuma guerra civil, mas que o partido era burguês e, por isso, perdeu a oportunidade. Ainda, em maio de 1968 os estudantes da Nanterre reclamavam seus direitos e foram ameaçados pelo governo gaullista. A ameaça fez parar, então, a Soborne a mais respeitada e renomada instituição da França no período, e o que se seguiu foi uma grande greve geral. Entre os estudantes a revolta era provocada especialmente pela inércia dos pesquisadores diante das condições históricas. Esse movimento fez com que muitos pesquisadores optassem por repensar seus estudos a partir das relações sociais. Mas é preciso fazer notar que o PCF não foi quem liderou o movimento, assim, os pesquisadores filiados ao Partido talvez, em um primeiro momento, responderam aos estudantes, mas não às condições de turbulência social. Por isso também, o contexto de produção entre os filósofos russos é distinto dos filósofos da década de 60 , não são conflitantes, são distintos.
} 
por serem heterogêneas, materializavam o antagonismo e a disputa pelo poder entre as classes.

Ao iniciarmos a discussão pela importância de Althusser, buscamos estabelecer o laço entre ele e seus dois alunos: Foucault e Pêcheux. Além disso, apontamos as categorias que constituíram nosso campo teórico de trabalho, pois como estamos trabalhando com a infraestrutura, é necessário também compreender como as formas de registro, feitas a partir das massas sociais, podem constituir-se em um deslocamento dentro da perspectiva da escrita da História dita oficial, reconfigurando tanto a memória como as formas de incidência nos discursos, em uma perspectiva foucaultiana da Análise do Discurso. Assim, passaremos à reflexão sobre a História, o Discurso e a Ideologia. Iniciemos nossa discussão pela História e, dentro dela, trataremos o conceito de Acontecimento. Para delinearmos a construção de História, partiremos da leitura feita por Dosse (1994) e pelo próprio Foucault (2005) para observarmos como o conceito de História é tratado.

Foucault ${ }^{4}$, de acordo com Dosse (1994), estava bastante envolvido com a leitura da, então chamada Escola de Annales ${ }^{5}$. A referida escola repensou o lugar da História a partir de 1929 com a publicação dos Anais de História Econômica e Social, de Lucien Febvre e Marc Bloch, abrindo um terreno para o que contemporaneamente será chamado de Nova História. São os dois autores que abrem a discussão para o fato de que a história não é o simples registrar e aglomerar de eventos em grandes blocos em que coubessem reis, soldados, plebeus.

A construção do objeto da história para Foucault é estabelecida a partir de uma relação que não ocorre pela recuperação da continuidade, de proveniência: as histórias das ideias são justapostas no tempo estabelecendo laços e regularidades que estão na forma como o historiador conduz o conjunto de discursos, no intuito de construir efeitos de

\footnotetext{
${ }^{4}$ Michel Foucault nasceu em 1924 em Poitiers. Historiador, crítico literário, filósofo, são algumas das denominações desse grande pensador. Engajado com as teorias das ideias contribuiu de maneira singular nas áreas da História, da Sociologia, da Análise do Discurso, etc., também foi diretor do Instituto de Filosofia na Faculdade de Letras da Universidade Clermont-Ferrand.

${ }^{5}$ A Escola de Annales foi um movimento de redefinição da História a partir da introdução da sociologia como método historiográfico. Capitaneada por Marc Bloch e Lucien Lebvre que eram editores e autores da revista Annales d'histoire économique et sociale que em 1929 passou a ser considerada um marco para a nova historiografia, a chamada Nova História. Entretanto, é preciso fazer uma ressalva que os primeiros trabalhos da Escola de Annales não tinham nenhum vínculo com o marxismo e até mesmo criticavam o Materialismo Histórico enquanto método. Por isso, quando olhamos para os escritos de Foucault que teve, como apontou Veyne (1998), influência da Annales é importante lembramos de tais considerações, pois Foucault deixará de tratar das questões marxistas em seus escritos.
} 
discursos de verdades. Para Foucault (2005), em A Arqueologia do Saber, a história genealógica é a tentativa de reunir regularidades em torno do acontecimento, não o tratando como algo da ordem da emergência: aquilo que surge, mas, tomando o acontecimento como aquilo que nos cerca, nos constrói. A contingência não é a incerteza dos desdobramentos da história, pois a história está desdobrada dentro do próprio acontecimento. Nesse sentido, a arqueologia da história foucaultiana não se interessa pela construção de um percurso historiográfico que trate da história da própria História, mas

procura somente estabelecer a regularidade dos enunciados. Regularidade não se opõe, aqui, à irregularidade que, nas margens da opinião corrente, ou dos textos mais frequentes, caracteriza o enunciado desviante (anormal, profético, retardatário ou patológico); designa, para qualquer performance verbal (extraordinária ou banal, única em seu gênero ou mil vezes repetida), o conjunto das condições nas quais exerce a função enunciativa que assegura e define sua existência. A regularidade, assim entendida, não caracteriza uma certa posição central entre os limites de uma curva estatística - não pode, pois, valer como índice de frequência ou de probabilidade; especifica um campo efetivo de aparecimento. Todo enunciado é portador de uma certa regularidade e não pode dela ser dissociado (FOUCAULT, 2005, p. 163).

As regularidades que se desdobram em diferentes saberes são, no discurso, por exemplo, responsáveis pela constituição de um conjunto de enunciados dentro de uma Formação Discursiva que, em Foucault (1995), têm relação com o acontecimento à medida que este inscreve as formas do dizer em um campo discursivo. Nesse contexto também, de acordo com Candiotto ${ }^{6}$ (2007) em Verdade e Diferença no pensamento de Foucault, a verdade é ressignificada. Portanto, não há uma verdade a ser retomada pela busca da origem - por meio da perenidade, da constância - a verdade é construída, justamente, na relação do enunciado com o acontecimento. $\mathrm{O}$ acontecimento molda o enunciado à sua existência, mas não o limita à acontecimentalidade e nisso reside a regularidade da qual trata Foucault: o enunciado carrega as marcas da discursivização do acontecimento.

Na mudança da perspectiva da forma como a História é compreendida há uma desconstrução da homogeneidade do campo histórico. Sendo assim, os elementos que antes eram os responsáveis pela continuidade, pela totalização da escrita e tentativa de controle da dispersão são agora insuficientes, pois as práticas discursivas, dos diferentes grupos,

\footnotetext{
${ }^{6}$ Professor do Programa de pós-graduação em Filosofia da Pontifícia Universidade Católica do Paraná. O texto em questão encontra-se na Revista Kriterion: Revista de Filosofia, n. 48, v. 115, de 2007. Disponível em < http://www.scielo.br/pdf/kr/v48n115/a1248115.pdf> acesso em janeiro de 2016.
} 
esferas sociais, etc., passam a compor as fontes, não como um procedimento de buscar o que falta na escrita universal como uma releitura do documento, mas sim buscar nas dispersões as regularidades que são próprias do acontecimento, a descrição do discurso, daquilo que Ihe é peculiar. Essa reconfiguração da compreensão do que é a história, ou do método analítico da história, tem uma profunda relação com as questões que da Escola de Annales e com a metodologia que esta adota diante da vida:

A história nova ampliou o campo do documento histórico. Ela substituiu a história [...] fundada essencialmente nos textos, nos documentos escritos, por uma história baseada na multiplicidade de documentos figurados, produtos de escavações arqueológicas, etc. (LE GOFF, 2013, p. 28). ${ }^{7}$

Aqui também o termo arqueologia assume outro caráter o que, juntamente com a revolução documental marcada pela heterogeneidade, será fundamental para Foucault em Arqueologia do Saber (1995). É nesse sentido que a contribuição de Foucault é genuína, pois, ao refletir a História como base nos escritos da Escola de Analles, ele desestabiliza a questão do objeto de análise, pois se Marx e Engels, em A ideologia Alemã (2007) tinham pensado a História como situada na base das forças produtivas, Foucault (1999) avançou na questão para refletir como a tensão pela disputa do poder incidia de forma prática na ordem da história, por meio das práticas e relações discursivas e do registro da história.

Dessa forma, é ao método arqueológico que Foucault recorrerá para estabelecer a diferença entre o sistema da similitude e o sistema de análise como modos de registro da história das ideias e organização da linguagem. No sistema das similitudes, a semelhança estabelecida entre as coisas do mundo: "conhecer as coisas era patentear o sistema de semelhanças que as tornavam próximas e solidárias umas das outras" (FOCAULT, 1999, p. 57). A linguagem era então uma tentativa de reconstruir, por meio de enunciados próximos, comentários, o discurso da origem, o discurso anterior a Torre de Babel. A arbitrariedade do signo se explicaria pela tentativa da palavra tentar recompor-se com o objeto, pela ordem da escrita, as palavras são as coisas. Nesse sentido, o privilégio da escrita, para Foucault (1999)

\footnotetext{
${ }^{7}$ Le Goff reconduz questões marxistas para a Nova História, pois, em princípio Bloch e Lefbvre contornaram o Materialismo histórico por meio da análise das relações sociais, assim, os movimentos das forças produtivas e o que eles tratavam por determinismo econômico ficavam diluídos nas relações das formas sociais. Foucault, de acordo com Zandwais (2013), era anarquista e, por isso, a Nova História passou a ser um campo produtivo, uma vez que se distanciava das instituições e mesmo da escrita da história institucionalizada. Desse modo, deslocamento provocado por Foucault na concepção da História é singular.
} 
em As palavras e as coisas, é o resultado da constituição no século XVI, de "uma superfície única e lisa, onde o olhar e a linguagem se entrecruzam ao infinito" (p. 54). A linguagem passa a encadear, por meio da ordem, as relações temporais e espaciais e a gramática se torna uma tentativa de estabelecer, por meio das palavras, a sucessividade: um acabamento temporal, lógico, capaz de representar sem desvios a lógica da linguagem. A reconstrução de como a linguagem era considerada para um e para outro método reforça a posição foucaultiana de que a História, em sua abordagem convencional, lidaria com a continuidade e as mudanças seriam tratadas como parte do processo de refinamento, da racionalidade da ciência que se presta a validar as regras da sucessividade, incluindo, por exemplo, o erro como uma espécie de critério para a evolução.

Assim, retomando a discussão da Escola de Analles, Foucault (2005), em a Arqueologia do Saber, reformula o lugar da história:

Digamos, para resumir, que a história, em sua forma tradicional, se dispunha a 'memorizar' os monumentos do passado, transformá-los em documentos e fazer falarem estes rastros que, por si mesmos, raramente são verbais, ou que dizem em silêncio coisa diversa do que dizem; em nossos dias, a história é o que transforma os documentos em monumentos e que desdobra, onde se decifrava rastros deixados pelos homens, onde se tentava reconhecer em profundidade o que tinha sido, uma massa de elementos que devem ser isolados, agrupados, tornados pertinentes, interrelacionados, organizados em conjuntos. Havia um tempo em que a arqueologia, como disciplina dos monumentos mudos, dos rastros inertes, dos objetos sem contexto e das coisas deixadas pelo passado, se voltava para a história e só tomava sentido pelo reestabelecimento de um discurso histórico; poderíamos dizer, jogando um pouco com as palavras, que a história, em nossos dias, se volta para a arqueologia - para a descrição intrínseca do monumento (FOUCAULT, 2005, p. 8).

A consequência desse movimento é que a noção de descontinuidade deixa de ser vista como estigma e passa a ser a condição determinante para que o acontecimento não seja analisado sob a ordem da sucessividade e, sim, no seio da disputa de poder. Sem a tentativa da construção, via história, da origem, ou melhor, do retorno à origem, o discurso é tomado como prática. Assim, também o descontínuo passa "do obstáculo à prática" (FOUCAULT, 2005, p. 10), não rompe o discurso eterno da história como uma ferida mal curada pelo historiador, mas é no descontínuo que se constrói tanto o objeto da história como a sua análise. O acontecimento é fundante do descontínuo e a História, no contexto foucaultiano, deveria ocupar-se de como as palavras e os discursos eram eleitos a partir dos 
acontecimentos e, assim, tornados "raros" em detrimento dos demais discursos. A linguagem, então, passaria a ser observada como aquela que contém as demais formas, por isso a dispersão, as séries fragmentadas (as muitas versões, os diferentes modos de discursivização, os diferentes gêneros do discurso) diriam mais sobre o acontecimento do que o discurso feito sobre ele pela história.

A discussão proposta por Foucault (2005) é a de que modo a História organiza e se relaciona com os documentos/monumentos de forma a fazer com que o conjunto de séries (entendidas aqui como os sistemas de pensamentos, as instituições, os campos de saberes) estabelecem entre si "o jogo das correlações e das dominâncias" (p. 11). Entretanto, tais relações não estão no campo da sucessividade, por isso o conjunto de dispersões localiza-se justamente nos desníveis, na não simetria entre as Formações Discursivas ou entre os saberes distintos de uma FD, pois é nesse momento que se observa o esforço da História em recompor a linearidade, criando por meio do movimento de construção da planificação dos acontecimentos, a ruptura, "na paradoxal noção de descontinuidade: é, ao mesmo tempo, instrumento e objeto de pesquisa, delimita o campo de que é o efeito, permite individualizar os domínios, mas só pode ser estabelecida através da comparação desses domínios"(FOUCAULT, 2005, p. 10).

Parece-nos que o autor, por meio do tratamento paradoxal da descontinuidade, volta a um conceito fundamental do marxismo: a contradição. Assim, a base da constituição do que Foucault (2005) trata por quadro - o conjunto das relações entre as distintas séries - é a própria contradição entre essas séries.

Nesse contexto, é que o acontecimento também é fundante das séries que serão a base da descontinuidade da História. Para o autor, o movimento da Nova História é o de não tratar o acontecimento como um evento apoteótico, pois o registro do acontecimento é heterogêneo, assim como a sua duração e seus processos de discursivização. E, sobre a temporalidade dos acontecimentos que, em nosso entendimento, apazigua a relação entre o acontecimento que se configura como um evento histórico e aquele que não aparece em nenhum livro de história, mas que também foi discursivisado, o autor argumenta

Daí a necessidade de distinguir não mais apenas acontecimentos importantes (com uma longa cadeia de consequências) e acontecimentos mínimos, mas sim tipos de acontecimentos de nível inteiramente diferente (alguns breves, outros de duração média, como a expansão de uma técnica, 
ou uma rarefação da moeda; outros finalmente, de ritmo lento, como um equilíbrio demográfico ou o ajustamento progressivo de uma economia a uma modificação do clima); daí a possibilidade de fazer com apareçam séries com limites amplos, constituídas de acontecimentos raros ou de acontecimentos repetitivos (FOUCAULT, 2005, p. 8/9).

Para Veyne (1998) ${ }^{8}$ em Como se escreve a história e Foucault revoluciona a história, a descontinuidade é o que determina o tecido de incoerência da história, pois, enquanto ciência a história atende aos interesses dos historiadores, por isso não é neutra, já que atende às forças super e infraestruturais. Sendo que, no primeiro caso, a força, o alcance e o valor de verdade são sempre maiores; enquanto que, no segundo caso, as histórias da infraestrutura aparecem como lugares de irregularidades na História oficial, mas de modo tal que as forças dominantes não consigam mais apagar a existência dos movimentos sociais, apenas tentar conter os efeitos de significação que eles possam produzir.

Ainda para Veyne (1998) os acontecimentos "não são coisas, objetos consistentes, substâncias; ele é um corte que realizamos livremente na realidade, um aglomerado de procedimentos em que agem e produzem substâncias de interação, homens e coisas" (p. 45), excetuando o advérbio livremente, pois a liberdade de escolha dos historiadores é, antes, também um aparecimento do sujeito, uma tomada de posição. Veyne indica não ser possível uma classificação dos acontecimentos que não seja determinada pelas tensões provocadas pela disputa de poder.

Nesse sentido, poderíamos inferir que o acontecimento, fora da ordem positiva da história, está na tensão entre super e infraestrutura, nas relações sociais estabelecidas no cotidiano e que fazem o sujeito emergir. Para exemplificar tal questão tomando a questão tomando como materialidade a comparação entre a finalidade do Plano de Estudos para Escolas Itinerantes do MST (FREITAS;CALDART;SAPELLI, 2013) e a finalidade das Diretrizes Curriculares do Estado do Paraná (DCE). A organização do Currículo do MST é pautada no diálogo com a própria experiência do MST e tem objetivo:

Contribuir na formulação de um projeto educativo comprometido com a construção da sociedade do trabalho, com igualdade social e participação plena de todas as pessoas, conforme suas necessidades e capacidades, nos processos de decisão e de produção da vida, em todas as suas dimensões (p.9)

\footnotetext{
${ }^{8}$ Arqueologista e historiador que, a partir da leitura foucautina da História, pensou sobre o lugar do acontecimento.
} 
A construção do currículo escolar é a edificação dos princípios políticos, educacionais, pedagógicos e filosóficos no espaço da escola, bem como a definição de quem são os sujeitos que farão parte de tal espaço, que no caso do MST tem o objetivo de "formar seres humanos mais plenos e que sejam capazes e queiram assumir-se como lutadores, continuando as lutas sociais de que são herdeiros" (idid,p.9)

Já a proposta das Diretrizes Curriculares do Estado do Paraná (2008) trata o currículo da seguinte maneira:

Assumir um currículo disciplinar significa dar ênfase à escola como lugar de
socialização do conhecimento, pois essa função da instituição escolar é
especialmente importante para os estudantes das classes menos
favorecidas, que têm nela uma oportunidade, algumas vezes única, de
acesso ao mundo letrado, do conhecimento científico, da reflexão filosófica
e do contato com a arte. (p.14)

O currículo, nesta perspectiva, agrupa, assim como faz a História oficial, um conjunto de saberes considerados fundamentais do ponto de vista do Estado, que são divididos em disciplinas que "orienta para uma aprendizagem específica, colocando em perspectiva o seu aspecto formal e instituído, o qual diz respeito aos conhecimentos historicamente sistematizados" (ibid.,p.15)

Além disso, para as Diretrizes os sujeitos constituintes do processo educacional do Estado são “os sujeitos da Educação Básica, crianças, jovens e adultos, em geral oriundos das classes assalariadas (...)"(PARANÁ, DCE, 2008, p.14), ou seja, os filhos de trabalhadores, o que nos leva a refletir que a escola do Estado cumpre o papel de educar tais parcelas da população como se tal tarefa fosse, para além da obrigação legal, uma espécie de mostra de generosidade do Estado, efeito de sentido possível, especialmente pelas enunciados "classes menos favorecidas", têm nela uma única oportunidade, algumas vezes única", desvalorizando toda a existência histórica e social que precede e circunda o espaço escolar.

Os exemplos acima nos mostram como a construção do currículo do MST, inscreve o Movimento na não linearidade histórica em que o ensino, assim como a própria narrativa histórica é tratado no eixo da sucessividade e linearidade, de forma massificada. Ao defender a construção de uma pedagogia do Movimento, o MST rompe com uma das principais formas de manutenção das formas de produção que é a reprodução no espaço escolar - sob a alegação de neutralidade - dos saberes e práticas das classes dominantes e 
que detém os meios de produção. Por isso, a o currículo estatal tem como sujeitos da educação aqueles oriundos da das classes assalariadas, ou seja, que recebem salário - a expressão material da venda da mão-de-obra. Por outro lado, dentro da proposta educacional do MST, há uma tentativa de formar sujeitos para luta, para militância, para a resistência.

Vayne (1998), ainda continuará o questionamento da história oficial ao tratar da história não-factual, ou seja, os eventos não consagrados, registrados como fatos pela história oficial: "a história das localidades, da loucura ou da procura de segurança através dos tempos" (p. 27). As questões levantadas, então, são "qual é a lógica da história? A quais interesses ela responde? E o que é o acontecimento para a história?" A lógica da história não pode ser encontrada na base da narração dos eventos históricos, mas na tensão da luta de classes, na relação entre a super e a infraestrutura. A história, Como gênero da superestrutura, é lógica, trata dos grandes fatos, apresenta uma sequencialidade, uma narratividade.

De acordo com Zandwais $(2015)^{9}$, para essa perspectiva não há pontos de dispersão, tudo parece no devido lugar: passamos dos grandes impérios para as navegações como se estivéssemos dentro de um romance inquestionável. A sedimentação de tais fatos cria rede de significações que tendem à estabilidade, entretanto, a narratividade da história não pode estar desvinculada da articulação política. Para explicarmos, voltemos a Veyne (1998):

\begin{abstract}
A história biográfica e anedótica, que está bem embaixo na escala, é uma história fraca que não contém sua própria inteligibilidade, e só quando transportada, em bloco, para dentro de uma história mais forte do que ela, é que lhe advém essa inteligibilidade. Contudo, estaríamos enganados se acreditássemos que esses encaixes reconstituem, progressivamente, uma história total, pois o que ganha de um lado perde-se de outro. A história biográfica e anedótica é a menos explicativa, mas a mais rica do ponto de vista da informação, já que considera os indivíduos em suas particularidades e detalha, para cada um deles as nuances do caráter, a sinuosidade de seus motivos, as etapas de sua deliberação. Essa informação é esquematizada e depois abolida, quando se passa a histórias cada vez mais fortes (p. 26).
\end{abstract}

O registro da história, nessa perspectiva não pode ser definido à priori, pois se voltarmos à questão da luta de classes e como ela determina os sujeitos no campo da

\footnotetext{
${ }^{9}$ Disciplina Tópicos em Análise do Discurso: sentido e referência. Programa de Pós-Graduação em Letras, Estudos da Linguagem: Teorias dos textos e dos discursos. UFRGS: Porto Alegre, primeiro semestre de 2015.
} 
prática, o registro da história dita oficial sempre será tomado como verdadeiro, assim como o registro dos movimentos da infraestrutura são tomados como anedóticos, não fundamentais. Assim, cria-se o efeito de que a história "verdadeira", que conta os fatos que realmente existiram é aquela alicerçada nas demandas da superestrutura e nos caudatários do poder. Aqui também se encontra a relação nodal da história com o político, ou a construção do efeito de verdade da história: só há história se ela narrar os gêneros da superestrutura, caso contrário, é uma não história, a história não oficial. Ainda, é Plekhanov (2000) em O Papel do Indivíduo na História que nos mostrará a relação da ciência com a história, pois para o filósofo "os homens fazem a sua história procurando atender duas necessidades e a ciência deve explicar como influem as diferentes formas de satisfação dessas necessidades nas relações sociais dos homens e na sua atividade espiritual" (p. 63). A explicação que a ciência dever fornecer é justamente a construção, no interior do Materialismo Histórico, de uma metodologia que não esteja ligada à desarticulação do ser de sua atividade social. Ou seja, é na relação das forças produtivas constituídas no cerne da luta entre as classes que nascem as ciências que se ocupam da ideologia da infraestrutura e como vai narrar e compreender a língua dos movimentos sociais. É nessa perspectiva também que Plekhanov (1989) vai afastar o acontecimento da causalidade e centrá-lo no interior das relações de produção, ou seja, casualidade é tudo aquilo que tenta apagar o caráter da luta de classes do acontecimento.

Paul Henry (1992), ao explicar a questão da ciência, toma de Marx a explicação do processo científico e ela nos interessa justamente pelo fato de que o registro da história, enquanto ciência, é feito sob a lógica das ciências burguesas:

A contribuição decisiva de Marx para a teoria do processo de produção do conhecimento científico deve-se à relação que ele estabelece entre a forma-sujeito do político e a forma-sujeito do conhecimento científico. No campo da complementaridade, essas duas formas-sujeitos estão separadas na neutralidade da Ciência; Marx estabelece o princípio da subordinação da segunda à primeira e, ao mesmo tempo, o processo de produção do conhecimento científico cai no campo da luta de classes. (HENRY, 1992, p. 128).

A questão fundamental é que não há ciência neutra. Por isso, a História enquanto ciência também não é. Pois os interesses que regem o fazer científico extrapolam as questões apenas da ciência para abrigarem-se no campo político. Assim, uma história que 
não seja a oficial deve se ocupar de resgatar os sujeitos que não estão inscritos na ordem lógica das verdades ontológicas, das ciências régias; e sim, resgatar a história dos sujeitos inscritos na cotidianidade, a história das relações fabris, das conversas entre vizinhos, no não-factual, considerando os acontecimentos como parte de um processo que não cessa de acontecer e descontinuamente se organiza no tecido da História. E Zandwais (2015), ao discutir a noção de acontecimento, aponta para importância que o conceito adquire para a filosofia da linguagem, a partir da ótica materialista, pois para autora, o acontecimento só pode ser compreendido se considerada a tensão entre a infra e a superestrutura.

\section{A LÍNGUA (DES)CONSTRUÍDA}

Um exemplo da materialidade dessa tensão pode ser observado no funcionamento da modalidades linguísticas. A Língua Portuguesa desembarcou com os colonizadores. O contato entre as línguas indígenas e a Língua Portuguesa resultou do apagamento - quase por completo das primeiras - em favor da última. A imposição feita pelos colonizadores, a qual foi levada a cabo pelos religiosos, criou um efeito similar ao que aconteceu com a posse da terra. Dessa forma, a língua que aqui existia não servia para a produção; os povos que aqui viviam, da forma como estavam, não serviam para o comércio com o restante do mundo. Nem suas línguas que eram ágrafas representavam os interesses dos dominadores. O processo de colonização teve como um dos seus componentes fundamentais a imposição da língua que passou a ser um instrumento de dominação e poder. Assim, para legitimar a posse das terras, a Coroa impõe a sua língua: o Português lusitano e o seu sistema gramatical que passa a ser o único válido.

Nesse contexto, tomaremos para discutir a institucionalização da língua oficial no Brasil o livro Histórias das Ideias Pedagógicas no Brasil de Saviani ${ }^{10}$ (2013). Para o autor tal institucionalização do ensino é um processo que começa, por meio da Igreja, com a chegada dos jesuítas em 1549, chefiados pelo padre Manoel da Nóbrega. Sendo assim, os jesuítas instituem um método de educação formal em solo brasileiro para alcançar de imediato duas questões: a catequização da população indígena por meio da linguagem e a facilitação dos trabalhos de conversão à fé católica. As reduções jesuíticas eram também o lugar de

\footnotetext{
${ }^{10}$ Livre-docente em História da Educação da Unicamp. Saviani é responsável, no Brasil, pela Pedagogia histórico-crítica que tem como base metodológica o Materialismo Histórico e a reflexão das bases pedagógicas a partir de uma perspectiva marxista.
} 
instrumentalização e oficialização da língua, por isso Saviani (2013), em História das ideias pedagógicas no Brasil, vai apontar que o processo de colonização no Brasil

\begin{abstract}
Abarca, de forma articulada, mas não homogênea ou harmônica, antes dialeticamente, esses três momentos representados pela colonização propriamente dita, ou seja, a posse e exploração da terra subjugando os seus habitantes (os íncolas); a educação enquanto aculturação, isto é, a inculcação nos colonizados das práticas, técnicas, símbolos e valores próprios dos colonizadores; e catequese entendida como a difusão e conversão dos colonizados à religião dos colonizadores. (p. 29)
\end{abstract}

O autor também defende a questão de que a organização da população indígena atendia as necessidades em torno da questão do gênero e do trabalho $e_{L}$ ao desembarcar no Brasil, os primeiros colonizadores tiveram não apenas que enfrentar a natureza, mas também a organização sistemática das populações que aqui viviam e para isso organizaram, via jesuítas, a pedagogia brasílica (SAVIANI, 2013, p. 39), que tem seu início e formalização a partir de 1599 com o tratado Ratio Studiorum. Esse tratado tinha como objetivo intervir na língua, na cultura e na formação das crianças indígenas a fim de convertê-las para a fé católica e torná-las aptas e dóceis ao trabalho. A partir da educação jesuítica sistematizada, podemos observar que há também o que Mariani (2004), em seu estudo Colonização linguística, tratou por colonização linguística:

A colonização linguística é da ordem de um acontecimento, produz modificações em sistemas linguísticos que vinham se constituindo em separado, ou ainda, provoca reorganizações no funcionamento linguístico das línguas e rupturas em processos semânticos estabilizados. Colonização linguística resulta de um processo histórico de encontro entre pelo menos dois imaginários linguísticos e constituídos de povos culturalmente distintos - línguas com memórias, história e políticas de sentimentos desiguais. (MARIANI, 2004, p. 28)

No Brasil, a imposição da língua portuguesa não apenas reorganizou a ordem linguística existente, mas praticamente dizimou a língua das populações indígenas com a Reforma Pombalina que, a partir de 1957, determina o fim da educação jesuítica e passa a tratar a educação por meio da defesa do desenvolvimento cultural "do Império Português pela difusão de novas ideias de base empirista e utilitarista; pelo derramamento das luzes da razão" (SAVIANI, 2013, p. 80). Ou seja, a língua de prestígio era a portuguesa. Assim, em 1758, torna-se oficial o ensino e o uso de língua portuguesa no Brasil. Segundo Mariani 
(2004), no texto mencionado acima, a Legislação Portuguesa, o Diretório de 1758, que institui a obrigatoriedade da Língua Portuguesa, também é responsável pelo silenciamento das diferentes línguas faladas e usadas no Brasil colônia. “O Diretório intervém no processo de construção da identidade linguística brasileira, já que visa impedir a brasilidade de enunciar-se também em língua geral" (SAVIANI, p. 119), ou seja, somente a língua portuguesa era permitida. A violência simbólica imposta pela Coroa criou a necessidade da educação linguística que foi sendo sistematizada por meio da criação de escolas que atendessem os nobres desembarcados em terras brasileiras, os filhos dos que aqui já se encontravam e, por fim, atender à monarquia portuguesa que desembarcou no Brasil, em 1808. A Reforma Pombalina teve fundamental importância para a consolidação da gramática vernacular nos estudos a partir de 1759, com base na imposição de que as escolas passariam a ensinar a Gramática Latina e o Português. O efeito de memória provocado pela imposição pombalina remete a normatização/naturalização do Português como a língua nacional. A padronização segue nas escolas que agora atendem à necessidade das esferas sociais dominantes, sendo predominante nos estudos linguísticos o domínio da norma culta como possibilidade de ascensão social.

É nesse sentido, por exemplo, que a escola toma a língua padrão como o guia no processo de ensino aprendizagem, pois de acordo com Maurizio Gnerre (1998), em Linguagem, escrita e poder: “uma variante linguística 'vale' o que 'valem' na sociedade os seus falantes, isto é, vale como reflexo do poder e da autoridade que eles têm nas relações econômicas e sociais" (p. 7). A escola ocupa-se de ensinar a variante de prestígio, pois nenhuma outra ocupa um lugar de poder ou está vinculada às formas de poder dominante. Para o autor, a estabilização de uma variedade como aquela possível de identificar-se como língua nacional é um processo que tem relação com a ascensão de determinados grupos ao poder. Em nossa história de colonização, por exemplo, a língua de poder era a Portuguesa que, em especial na escrita, consolidou-se como a língua oficial. Gnerre (1998) ainda reforça o fato de que quando a língua escrita se consolida enquanto tal, ela organiza os conteúdos referenciais sobre a própria língua e por isso é capaz de estabelecer uma tradição gramatical. Assim, para o autor, estabelecer uma variedade linguística como sendo a dominante e organizá-la de forma sistemática é fundamental para o processo de legitimação e edificação da institucionalização linguística. Para o autor: 
A partir de uma determinada tradição cultural, foi extraída e definida uma variedade linguística usada (...) em grupos de poder, e tal variedade foi reproposta como algo central na identidade nacional, enquanto uma portadora de uma tradição de cultura. Assim como o Estado e o poder são apresentados como entidades superiores e "neutras", também o código aceito "oficialmente" pelo poder é apontado como neutro e superior, e todos os cidadãos têm de produzi-lo e entende-lo nas relações de poder (GNERRE, 1998, p. 8-9, grifos nossos).

Essa reflexão conjuga dois pontos sobre o quais tratamos anteriormente: o papel da escola enquanto reprodutora da cultura dominante; e, a manutenção de tal dominação pelo modo como a língua institui uma normatização das relações, apagando as histórias das variantes não-padrão, por vezes, ágrafas, como o caso das línguas indígenas. Esses dois mecanismos resultam, também, na construção de conceitos e saberes sobre língua(gem) que perpassam o espaço escolar. Essa prática linguística torna-se, então, uma prática política, como explicita Pêcheux (2009), em Semântica e Discurso, os aparelhos ideológicos são o lugar de realização da ideologia dominante. E, mesmo em uma escola de assentamento, podemos ver funcionando os argumentos sobre a língua que são marcados por essas ideologias, com a ressalva de que há nos saberes de Língua do MST, sempre um gesto de resistência que apontam para o fato de que a realização das práticas linguísticas dominantes não ocorrem de forma plena, mas sempre no campo da disputa, do desacordo. Tomemos, por exemplo, a resposta dada por um(a) educador(a) de língua portuguesa, de uma escola de assentamento para a seguinte questão: Qual concepção de Língua que você trabalha em sala de aula?

\footnotetext{
A língua é um instrumento de luta dos sujeitos, seja do ponto de vista individual ou coletivo. A língua (oralidade e escrita) deve ser ensinada e dominada como condição de humanização das pessoas. Dessa forma, não basta, ainda que importante seja, o domínio de regras que permitem uma escrita legível, porém, em muitos casos, vazias de conteúdo. Sendo assim, faz-se necessário articular o estudo da gramática articulada com os processos da vida que envolve as situações reais dos sujeitos. Em outras palavras, as regras gramaticais devem ser incorporadas nas questões presentes na realidade dos envolvidos no processo educativo, permitindo que palavra e mundo fundam-se para produzir sentido. Concepção de língua como prática social. A língua, encontra-se ligada aos processos sociais, transforma-se com o tempo, ao passo que também transforma aos sujeitos. ${ }^{11}$
}

\footnotetext{
${ }^{11}$ Grifos nossos
} 
A primeira questão para a qual gostaríamos de chamar atenção é o enunciado $a$ língua é um instrumento de luta dos sujeitos. Dessa forma, ela não é um instrumento de comunicação e não é uma forma de acesso social, inclusive, não é expressão do pensamento, ou seja, o rompe com as definições sobre o que seja língua em manuais de gramática ou nos materiais didáticos para construir uma definição própria e próxima das condições sociais nas quais está inserido

A língua como prática social pode ser caracterizada como a língua que pertence à coletividade das relações dos sujeitos em suas práticas sociais e, neste aspecto, há a conjunção de dois lugares teóricos que levantamos no primeiro capítulo: o modo como a pedagogia soviética reforçava a coletividade na constituição da realidade das formas de existência dos sujeitos; e, como, para Bakhtin/Volochinov/Medviédev, o meio ideológico era o centro de organização das formas da língua e ele só poderia ser entendido como sendo composto pela coletividade e pela realidade da existência dessa coletividade.

A língua que se encontra ligada aos processos sociais responde ao modo como as forças antagônicas disputam o poder e como esse conflito repercute, por exemplo, chamando os sujeitos a posicionarem ou a exporem o modo como participam desse processo tensivo, conforme observamos na análise da produção textual.

Dessa forma, chega-se à discussão proposta por Zandwais (2012), em Subjetividade, sentido e linguagem: desconstruindo o mito da homogeneidade, em que a autora argumenta que é preciso conhecer o corpo material da língua inserido em um corpo social de maior complexidade. Não há como negar as marcas desse corpo; além disso, o conceito de língua apresentado pelo educador inscreve as relações linguísticas no centro das questões políticas, pois tais relações são pensadas a partir das questões de emancipação dos sujeitos, considerando os 'falares nas classes excluídas, dominadas' como a forma fundamental de subjetivação dentro de um movimento de luta. Bakhtin/Volochinov (2004), em Marxismo e filosofia da linguagem, nos lembram que não é possível retirar do signo sua realidade material e esta está impregnada das formas multiformes de existência da língua, assim, mesmo em uma língua considerada única, como é o caso da Língua Portuguesa, as formas linguísticas vão manifestar posições ideológicas e relações de dominação.

Ao nos determos novamente no conceito de Medviédev (2012), levantado no primeiro capítulo, sobre o meio ideológico (p. 56), notaremos que o conceito de língua 
apresentado pelo educador $A$, em sua resposta, estabelece uma relação entre o conhecimento da língua e a formação da consciência. Isto é, não há sujeitos fora da vida, das relações sociais, dos lugares que as relações de produção estabelecem para cada um. Por isso, o enunciado contido na resposta: as regras gramaticais devem ser incorporadas nas questões presentes na realidade dos envolvidos no processo educativo, permitindo que palavra e mundo fundam-se para produzir sentido, são de uma importância singular, pois assim como a discussão proposta sobre a mídia, essa reflexão associa as questões linguísticas, de forma indissociável, às questões discursivas; sendo também um gesto de ruptura em relação ao entendimento e às práticas sobre a língua na escola gerenciada pelo Estado, já que a realidade mencionada é a da luta de classes.

Nesse contexto, a realidade em um assentamento não é a realidade da escola em um centro urbano. Sendo assim, toda a narrativa histórica monológica sobre língua, sobre o que é língua, perde o caráter de univocidade e de verdade, para estabelecer-se, ao lado da língua que se ensina no assentamento, como uma possibilidade de existência da língua. Essa desmistificação da língua homogênea provoca também uma desarticulação do gesto político - ou do gesto de política linguística, que 'fecha' as fronteiras em torno de uma língua de cultura (ZANDWAIS, 2012), estabelecendo no espaço escolar um descompasso que é baseado justamente no conflito entre a política de um movimento de resistência e a política do Estado. A língua como um instrumento de luta dos sujeitos é o rompimento com a ordem da igualdade da língua (língua nacional) e, além disso, é o uso da língua para um projeto que não está vinculado ao modo de produção dominante e, que por isso, escancara a luta de classes, ou seja, o confronto infindável entre aqueles que exercem a dominação e aqueles que lutam contra ela.

Pêcheux (2010), em Ler o Arquivo hoje, destaca que a cultura científica trata a língua como se ela fosse uma materialidade qualquer, mas que o faz transportando e inscrevendo a língua em outro lugar: "no espaço lógico-matemático onde, outra vez, a materialidade da língua é denegada, através das ilusões da metalinguagem universal” (p. 57). Assim, aprender a língua é, de alguma forma, penetrar nesse universo lógico em que o controle, o padrão, coloca todos em nível de igualdade. No entanto, ressaltamos que essa igualdade que os educadores/as tanto usam como argumento para o ensino da língua padrão é também uma 
ilusão. Para, Jacob L. Mey $(1998)^{12}$, em seu texto Etnia, identidade da língua, a língua vale o que vale seus falantes. Ou seja, a tentativa de uma homogeneização é uma tentativa de estabelecer um padrão linguístico valorado a partir de aspectos sociais. E essa tentativa tem por objetivo a fixação de um padrão que, neste caso, tem relação com o que acontece com o sistema de valores monetários: o dinheiro vale conforme estabelece uma relação com os meios de produção e seus processos. Sem essa relação, ou seja, sem estabelecer um vínculo com aquilo que realmente tem valor, o dinheiro perde o seu lugar, se descontextualiza. Essa metáfora monetária se faz presente para explicar que a língua comum (que tomaremos neste contexto como a padrão) é também uma medida fictícia, isto é,

A língua comum é a medida fictícia do ouro na nossa fala. Seu dialeto padrão - virtualmente inexistente - é tipicamente falado, na melhor das hipóteses, por muito poucos da população de um país. O valor de uma língua padrão, assim como valor do precioso metal, é dependente da sua descontextualização, o que quer dizer que representa o valor absoluto, ao mesmo tem em que, na realidade, não tem absolutamente nenhum valor concreto: é um padrão descontextualizado. (MEY, 1998, p. 80)

A descontextualização é a fonte do padrão, ou seja, para que ela seja considerada um padrão é preciso apagar as relações vívidas da língua com a forma como ela é organizada e produz sentidos. Essa descontextualização apaga a relação dialética da língua: a de formar consciência via material verbal; e, a de ser indissociavelmente vinculada a uma coletividade que organiza as formas sociais, as relações de interação e de antagonismo, as relações dialógicas e dialéticas que constituem a consciência.

Ainda, ao acrescentar à essa discussão de Mey, aquela de Gnerre (1998) e as considerações de Bakhtin/Volochinov (2004) em Marxismo e filosofia da Linguagem, podemos observar que há uma tentativa de linearizar a língua em torno de um sistema determinado - assim como o financeiro - por meio das forças sociais dominantes, a qual tem por objetivo estabelecer uma língua que seja considerada aquela a ser falada, escrita. $E$, ainda mantendo a analogia com o sistema financeiro, o modo de produção capitalista organiza seu sistema para manter a hegemonia dos detentores dos meios de produção; até existem outras modalidades de sistemas econômicos, mas são considerados

\footnotetext{
12 In. SIGNORINI, I. (Org). Lingua(gem) e identidade: elementos para uma discussão no campo aplicado. Campinas, SP: Mercado das Letras/FAPESP, SP, 1998.
} 
"experimentos", "anomalias", etc. Assim também acontece com as aquelas línguas que não atendem à língua padrão, passam a ser consideradas variantes, anomalias, etc.

Ainda para Gnerre (1998), esse ensino massificado da norma padrão pode, em um primeiro momento, parecer um processo democrático, uma vez que, supostamente, todos teriam condições iguais de saber sobre a língua. Entretanto, esse argumento logo se enfraquece, já que o estabelecimento de uma gramática normativa implica, necessariamente, em um apagamento das condições históricas de constituição, por exemplo, da Língua Portuguesa como oficial, isto é, a obrigatoriedade imposta pela lei; dessa forma, ocorre o silenciamento das sociedades ágrafas, assim como dos imigrantes. Esse apagamento, tratado por Bourdieu e Boltanski como amnésia das gênesis, conforme pontuou Gnerre (1998, p.28), institui os enunciados vazios sobre a língua, ou seja, as tautologias sobre a língua e seu ensino, como a justificativa da conquista de um lugar na sociedade, por exemplo, que, no campo da prática, contribuem para a legitimação de um conjunto de regras definidas e cristalizadas por força do poder da classe dominante e que têm como base o apagamento da relação entre língua, política e história. ${ }^{13}$

Essa relação entre a língua padrão e as outras línguas também pode ser abordada pela perspectiva de Rancière (1996) em O Desentendimento, para quem a questão de ter e não ter palavra está relacionada à desigualdade política, ou seja, os pobres, os plebeus, não têm palavra porque não falam e não falam porque são, da perspectiva da classe dominante, seres sem nome, "privados de logos, quer dizer de inscrição simbólica na pólis" (p. 37). A importância dessa reflexão é fundamental, pois não estamos dizendo que a gramática seja dispensável, mas estamos dizendo que o modo como o ensino e a imposição das regulamentações linguísticas são instituídas e, também, mantidas respondem ao modo como o poder dominante imagina a outra classe, como seres que precisam, se quiserem ter voz na sociedade, se adaptarem as regras de convívio, entre elas, as linguísticas.

\footnotetext{
${ }^{13}$ Retomando a questão dos gêneros que discutimos anteriormente, o processo de didatização proposto pelos PCNs sobre os gêneros dos discursos provoca justamente esse movimento de apagamento das questões ideológicas que são a base fundante dos gêneros, tratando-os apenas em seus aspectos linguísticos. Assim, para ter cidadania era preciso saber os gêneros institucionalizados. A distância dessa definição para o que Bakhtin (2003), em a Estética da Criação Verbal, trata como gêneros é bastante grande, mas a principal, em nosso entendimento é o apagamento da relação do gênero secundário (institucionalizado) com o gênero primário (aqueles que estão na vida). Para o autor, os gêneros primários são a base dos gêneros secundários, uma vez que não há gênero sem vida, sem o meio ideológicos onde os sujeitos interagem. Entretanto, os PCNs e os materiais didáticos que se seguiram a eles, passaram a tratar os gêneros secundários como o eixo de progressão curricular e, mais uma vez, estamos diante da língua padrão (aqueles que funcionam no Estado e suas instituições) como a dominante no espaço escolar.
} 


\section{CONSIDERAÇÕES}

Toda forma de materialidade simbólica precisa ser observada sobre os primas histórico, social e ideológico. Retomando Pêcheux (2010) a ilusão de fonte de sentido do dizer, por vezes, nos fornece o conforto necessário para não debruçarmos sobre o modo de funcionamento das formas ideológicas dominantes. Elas em si não representam a grande questão, mas o modo como são impostas sim, pois em um sistema impositivo, passamos da pluralidade para a unicidade e ao fazermos isso negamos a existência de vozes destoantes, de outras possibilidades de existência linguísticas (ou mantemos a existência de tal formas apenas no reconhecimento e aceitação).

A contribuição dos movimentos sociais (e no caso de nosso estudo, do MST) é pensar a língua como representativa de uma condição de resistência de uma parcela do corpo social que só de forma precária tem acesso aos bens públicos. Poderíamos retomar todo o debate sobre como o Estado, conforme reflexão althusseriana, se estabelece diante luta de classes e ao fazê-lo, pensamos o MST como um movimento fundamental para a configuração não apenas da luta como um todo, mas também na organização das representações simbólicas do desdobramento da luta pode trazer: saberes sobre escola (e currículo, saúde, ocupação da terra, relação com a natureza, cooperação e coletividade). A língua, no bojo de tal debate, apresenta-se como parte de uma construção em torno de novas modalidades da existência dos sujeitos. Por isso ela deixa o campo da normatividade para torna-se um instrumento de resistência e luta.

\section{REFERÊNCIAS}

ALTHUSSER, Louis. Sobre a Reprodução, Rio de Janeiro: Editora Vozes, 1999.

BAKHTIN, M.; VOLOCHINOV, V. N. Marxismo e filosofia da linguagem. 11 ed. Trad. Michel Lahud e Yara Frateschi Vieira. São Paulo: Hucitec, 2004.

BAKHTIN, M. Os Gêneros do Discurso. Organização, tradução, posfácio e notas de Paulo Bezerra; notas da edição russa de Serguei Botcharov. São Paulo: Editora 34, 2016.

BAKHTIN, M. Estética da Criação Verbal. 4 ed. Trad. Paulo Bezerra. São Paulo, 2003. 
BOURDIEU, Pierre. A economia das trocas simbólicas. Introdução, seleção e organização de Sergio Miceli. São Paulo: Perspectiva, 2013.

BRASIL. Parâmetros Nacionais Curriculares. Língua Portuguesa. Brasília: MEC/SEF, 1997.

MARTINS, Adalberto. Caderno de Cooperação Agrícola no.10: o que levar em conta na organização do assentamento. São Paulo: Confederação das Cooperativas de Reforma Agrária, 2001. Disponível em < http://www.reformaagrariaemdados.org.br/sites/default/files/Cadernos\%20de\%20coopera \%C3\%A7\%C3\%A30\%20agricola\%20n\%C2\%BA\%2010.pdf>. Acesso em julho de 2016.

CANDIOTTO, Cesar. Verdade e diferença no pensamento de Foucault. In. Kriterion: Revista de Filosofia, no.48, v.115, 2007.

FREITAS, L.C de. CALDART, R.S. M. L. SAPELLI. Planos de Estudo da Escola Itinerante. Veranópolis, RS:Setor de Educação, 2013.

FOUCAULT, Michel. As palavras e as coisas: uma arqueologia das ciências humanas. Trad. Salma Tannus Muchail. 8 ed. São Paulo: Martins Fontes, 1999.

FOUCAULT, Michel. A arqueologia do saber. 7 ed. Tradução de Luiz Felipe Baeta Neves. Rio de Janeiro: Forense Universitária, 2005.

FOUCAULT, Michel. A ordem do discurso. 5 ed. Trad. Laura Fraga de Almeida Sampaio. São Paulo: Edições Loyola, 1999.

GADET, F.; HAK T. Por uma análise automática do discurso: uma introdução à obra de Michel Pêcheux. 4 ed. Trad. Bethania S. Mariani et al. Campinas, SP: Editora da Unicamp, 2010.

GNERRE, Maurizio. Linguagem, escrita e poder. 4 ed. São Paulo: Martins Fontes, 1998 (Texto e Linguagem).

HENRY, Paul. A ferramenta imperfeita: língua, sujeito e discurso. Tradução: Maria Fausta de Castro. SP-Campinas: Ed. da UNICAMP, 1992.

LE GOFF, Jacques. História e memória. 7ạ. ed.Trad. Bernardo Leitão [et al]. Campinas, SP: Editora da Unicamp, 2013.

MARIANI, Bethania. Colonização Linguística. línguas, política e religião no Brasil (séculos XVI a XVIII) e nos Estados Unidos da América (século XVIII). Campinas, SP: Pontes, 2004.

MARX, K.; ENGELS, F. A Ideologia Alemã: crítica da mais recente filosofia alemã em seus representantes Feuerbah, B. Bauer e Stirner, e do socialismo alemão em seus diferentes profetas. Trad. Rubens Enderle, Nélio Schneider e Luciano Cavini Martorano. São Paulo: Boitempo, 2007. 
MEDVIÉDEV, P. N. O método formal nos estudos literários: introdução crítica a uma poética sociológica. Trad. Sheila Camargo Grillo e Ekatherina Vólkova Américo. São Paulo: Contexto, 2012.

MEY, Jacob L. Etnia, Identidade e Língua. In. SIGNORINI, M. I. (org) Lingua(gem) e identidade: elementos para uma discussão no campo aplicado. Campinas, SP: Mercado de Letras, FAPESP, 1998.

PECHEUX, M.Semântica e Discurso: uma crítica à afirmação do óbvio. 4. Ed. Tradução Eni Puccinelli Orlandi et al. Campinas; São Paulo: Editora da Unicamp (2009).

PECHEUX, M. Discurso: estrutura ou acontecimento. 2 ed. Trad. Eni Puccinelli Orlandi. Campinas, SP: Pontes,1997.

PECHEUX. M. Por uma análise automática do discurso: uma introdução à obra de Michel Pêcheux. 4 ed. Trad. Bethania S. Mariani et al. Campinas, SP: Editora da Unicamp, 2010.

PECHEUX, M. Ler o arquivo hoje. In. ORLANDI, E. P. (org) Gestos de Leitura: da história no discurso. 3 ed. Campinas, SP: Editora da Unicamp, 2010.

PLEKHANOV, G.V. Os princípios fundamentais do Marxismo. 2 ed. Tradução de Sônia Rangel. Editora Hucitec: São Paulo, 1989.

PLEKHANOV, G.V. O papel do indivíduo na história. São Paulo: Expressão Popular, 2000.

RANCIÈRE, Jacques. O desentendimento. Trad. Angela Leite Lopes. São Paulo: Ed. 34, 1996.

SAVIANI, Dermeval. História das Ideias Pedagógicas no Brasil. 4ed. Campinas, SP: Autores Associados, 2013.

SAVIANI, Dermeval. Escola e democracia : teorias da educação: curvatura da vara, onze teses sobre educação e política. 16 ed. São Paulo : Autores Associados, 1987.

SECRETARIA DO ESTADO DO PARANÁ. Diretrizes Curriculares da Educação Básica: Língua Portuguesa. Secretaria Estadual de Educação, Curitiba/PR, Imprensa Oficial, 2008.

VEYNE, Paul. Como se escreve a história e Foucault revoluciona a história. 4 ed. Trad. Alda Baltar e Mara Auxiliadora Kneipp, Brasília: Editora da Universidade, 1998.

ZANDWAIS, Ana. Subjetividade, sentido e linguagem: desconstruindo o mito da homogeneidade da língua. In: . História das ideias: diálogo entre linguagem, cultura e história. Passo Fundo: Universidade de Passo Fundo, 2012. p. 175-191.

ZANDWAIS, Ana. O funcionamento da subjetividade: um contraponto entre estudos comparatistas e a filosofia da linguagem russo-soviética. In. Conexão Letras 10: História das ideias: nos domínios da língua(gem). V.8. Porto Alegre: Universidade Federal do Rio Grande do Sul, 2013. 
ZANDWAIS, Ana. Disciplina Tópicos em Análise do Discurso: sentido e referência. Programa de Pós-Graduação em Letras, Estudos da Linguagem: Teorias dos textos e dos discursos. UFRGS: Porto Alegre, primeiro semestre de 2015.

Recebido em: 01 de Abril de 2020

Aceito para Publicação em 30 de Abril de 2020 